This item was submitted to Loughborough's Research Repository by the author.

Items in Figshare are protected by copyright, with all rights reserved, unless otherwise indicated.

\title{
Are genetic tests exceptional? Lessons from a qualitative study on thrombophilia
}

PLEASE CITE THE PUBLISHED VERSION

PUBLISHER

(C) Elsevier

VERSION

AM (Accepted Manuscript)

LICENCE

CC BY-NC-ND 4.0

\section{REPOSITORY RECORD}

Saukko, Paula, Suzanne H. Richards, Maggie H. Shepherd, and John L. Campbell. 2019. "Are Genetic Tests Exceptional? Lessons from a Qualitative Study on Thrombophilia". figshare. https://hdl.handle.net/2134/5637. 
This item was submitted to Loughborough's Institutional Repository (https://dspace.lboro.ac.uk/) by the author and is made available under the following Creative Commons Licence conditions.

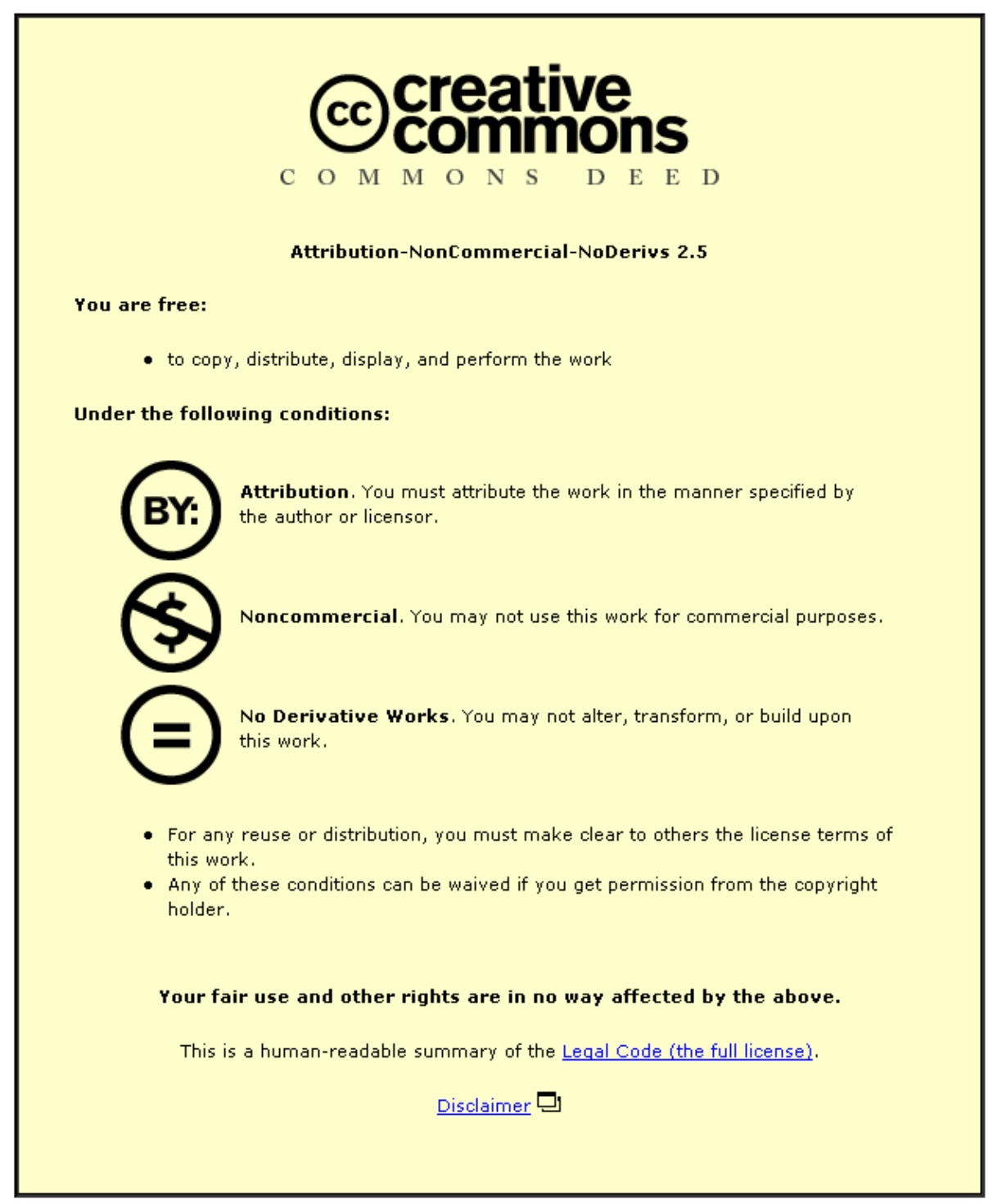

For the full text of this licence, please go to: http://creativecommons.org/licenses/by-nc-nd/2.5/ 
Ref. Saukko, P., Richards, S, Shepherd, M, Campbell, J. (2006). Are genetic tests exceptional? Lessons from a qualitative study on thrombophilia, Social Science \& Medicine, 63, 7, 1947-1959.

Version accepted for publication.

\title{
ARE GENETIC TESTS EXCEPTIONAL? LESSONS FROM A QUALITATIVE STUDY ON THROMBOPHILIA
}

\begin{abstract}
Policy makers have suggested that information about genetic risk factors, which are associated with low risk and for which preventive strategies exist, should not be considered “exceptional” and should not warrant special safeguards, such as data protection or specialist pre-test counselling. There is scant research on how such risk factors are perceived, and to explore this we conducted qualitative interviews with fortytwo participants, who had undergone testing for a low risk genetic susceptibility to deep vein thrombosis (DVT). Generally the participants thought the test was less serious than a genetic test for a predisposition to breast cancer or a non-genetic, diagnostic test for diabetes. They had used the genetic information to reduce their risk of DVTs by avoiding oral contraceptives and hormone replacement therapy but had not changed their lifestyle. Many participants considered pre-test genetic counselling unnecessary. However, a subgroup of participants, who were often less educated or at a high risk, were distressed and/or confused about thrombophilia and thought pre-test counselling would have been helpful. The findings indicate an emerging interpretation of genetics not as revealing exceptional or “in depth” knowledge about one’s health and identity but as occasionally relevant surface information, which participants used to make specific health decisions
\end{abstract}


but not to transform their everyday lives. However, the views of the subgroup remind that some participants interpret thrombophilia as serious and/or need special support.

\section{Introduction}

The UK Human Genetics Commission (2002), Department of Health (2003) and the US Secretary's Advisory Committee on Genetic Testing (2001) have recently suggested that the argument that all genetic information is "exceptional" and warrants special safeguards, such as additional data protection or pre-test counselling, is an outmoded paradigm. These policy-initiatives have proposed that genetic tests with "low" and "intermediate" impact should not be classified as exceptional. On the contrary, detecting individual's genetic susceptibility to cardiovascular disease, diabetes or cancer could in the future enable general practitioners and practice nurses to target preventive treatments, lifestyle advice and screening to those at increased risk (Department of Health, 2003, also Ross, 2001).

However, there is scant research on whether patients perceive low risk, genetic susceptibilities, for which preventative strategies exist, as special or exceptional or not. Research has identified diverse "lay epidemiologies" that mediate individuals' sense of vulnerability to familial risk (Hunt et al, 2001, Walters et al, 2004). Qualitative research on patient experiences of familial hypercholesterolaemia (Senior, Marteau \& Peters, 1999, Senior et al, 2002) and genetic susceptibility to hemochromatosis (Bharadwaj, 2002, Bharadwaj et al, in press), for which preventive strategies exist, has observed that different groups of patients may have significantly different perceptions of the conditions, ranging from feelings of indifference and being in control to fatalism and resentment for 
not being diagnosed earlier. More generally, it has been suggested that testing for genetic susceptibilities may medicalise healthy but “at risk” individuals (Melzer \& Zimmern, 2002) and overplay the role of genes in the development of common, complex diseases (Petersen \& Bunton, 2002).

In light of these discussions, we explored whether patients, who had undergone genetic testing for a low risk susceptibility to deep vein thrombosis (DVT), perceived the test results to be different from other medical information or to predict their health. We also explored how patients used the genetic information to prevent DVTs and whether they thought specialist counselling should be offered prior to testing.

\section{$\underline{\text { Genetic Exceptionalism }}$}

Genetic exceptionalism is a bioethical concept, coined by Murray (1997), who borrowed it from "HIV exceptionalism”. Like the diagnosis of HIV, genetic test results have been argued to be different from, and potentially more harmful than, other types of medical information. It has been suggested that genetic information is special, because it is immutable throughout the lifecourse, sometimes determines or predicts a future illness, can lead to social discrimination or psychological anxiety, can be used for other purposes (paternity testing, forensic research) and has implications for others (family members)

(e.g. Human Genetics Commission, 2002: 30). Because of the conceptualization of genetic tests as exceptional, special safeguards, such as anti-discrimination laws (Rothstein, 2005) and special consenting protocols, such as pre-test counselling and written informed consent (Annas, Glantz \& Roche, 1995) have been established or recommended to protect patients from harm. 
Lately, it has been argued that exceptionalism is an outmoded concept. It has been claimed that genetics-focussed anti-discrimination laws merely masque the wider problem of discrimination based on health and disability by employers and insurers (Rothstein, 2005). It has also been argued that granting special status to tests that detect inherited susceptibilities to conditions caused by complex gene-environment interaction may fuel genetic determinism (Murray, 1997, Ross, 2001, Green \& Botkin, 2003, Everett, 2004, Rothstein, 2005). Ross (2001) has noted that the development of effective treatments has transformed the focus in HIV-testing from protecting anonymity to identifying individuals who may have contracted the virus in order to offer them treatment. Ross argues that in a similar way identifying genetic susceptibilities, for which there are effective preventive treatments, should change the focus in public policy on genetics from protecting an individual's privacy to enhancing public health benefits.

The US Secretary's Advisory Committee on Genetic Testing (SACGT) of the National Institutes of Health and the UK Human Genetics Commission (HGC) have attempted to distinguish between low and high impact genetic tests that require and do not require special legal protection and special consenting procedures. It has been argued that predictive tests are more exceptional than diagnostic tests, and tests that identify conditions with high penetrance (likelihood that the DNA-sequence will lead to an illness) are more exceptional than those with low penetrance. It has also been suggested that tests that identify conditions for which no cure or treatment exists are more exceptional than those that detect conditions that can be treated or prevented (SACGT, 2001; HGC, 2002). For example, the genetic test for Huntington’s disease, which identifies individuals who will nearly certainly develop an incurable, fatal 
neurodegenerative disease in mid-life, is considered exceptional. On the contrary, the genetic test for phenylketonuria (PKU), which identifies a condition that can be effectively treated in newborns but, if undetected, can cause serious harm, is not considered exceptional but is routinely performed in the UK.

However, many genetic tests are not as clear-cut as these two extremes. For example, genetic tests for susceptibility to common diseases may identify mostly low and preventable risk, but it is uncertain how patients perceive these risks, how they act upon them in terms of prevention and whether they feel they would benefit from special support. Regardless of high expectations and research activity in this area (e.g. Watkins \& Farrall, 2006), the UK National Health Services (NHS) currently offers only two tests that fall within this category: the genetic tests for susceptibility for deep vein thrombosis and for hemochromatosis. Other tests of disputed utility are available commercially (Haga, Khoury \& Burke, 2003).

Thrombophilia is a polygenic condition associated with five gene alterations: Factor V Leiden (FVL) ${ }^{1}$, Prothrombin, Protein S Deficiency, Protein C Deficiency and Antithrombin Deficiency. It is common (the most prevalent alteration, FVL is present in 1:25 of Caucasians) and associated with low risk (healthy individuals, who are heterozygous for FVL, are estimated to have approximately $0.6 \%$ annual risk of a DVT) (Middeldorp, 2001). Preventive strategies include avoidance of oral contraceptives and hormone replacement therapy, prophylactic anti-coagulants in high risk situations, caution during long flights and avoidance of overweight and smoking. Thrombophilia receives much less public attention than breast cancer genetics, but it is the most common genetic test in the US (Hellmann et al 2003) and one of the most common ones in the 
UK. ${ }^{2}$ Testing for thrombophilia can be managed by primary and secondary care clinicians, without necessary involvement of clinical genetics (see Walker, Greaves \& Preston, 2001; Grody et al 2001). Thus, thrombophilia offers a good case for empirical exploration of how feasible the abstract bioethical and policy propositions about genetic exceptionalism are from a patient point of view.

\section{Perceptions of Genetic Risk}

There is a growing literature, deriving from both quantitative and qualitative research, on patient perceptions of genetic risk. Most of this literature focuses on singlegene disorders, such as familial hypercholesterolaemia or hereditary breast and ovarian cancer, associated with high risk or on family history of disease, such as heart disease. Still, it offers insights on the factors that are likely to mediate whether individuals perceive a low risk genetic risk to be exceptional in terms of being more or less severe/ penetrant, treatable or preventable and having unusual psychological and social consequences.

Factors affecting people's estimates of the severity of their personal risk in relation to familial risk include the number of relatives affected, their emotional closeness to or physical or psychological resemblance of those affected, witnessing a relative's illness or death and counter examples, such as relatives, who lived to ripe old age (e.g. Hunt, Emslie \& Watt, 2001; Walter et al 2004; Walter \& Emery, 2005). Risk perceptions are also affected by personal, embodied experience of the illness, such as breast cancer (Hallowell et al 2004). Bharadwaj discovered that individuals who were identified with a genetic susceptibility to hemochromatosis were indifferent to the low risk (Bharadwaj, 
2002), whereas individuals who had developed the condition were often intensely engaged with the condition and resentful for not been diagnosed earlier (Bharadwaj et al, in press).

People have also been observed to make sense of the seriousness of a genetic risk by comparing it to other illnesses (Senior et al, 2002; Petersen, in press). Furthermore, different illnesses carry different associations, cancer being perceived as leading to a lingering, painful death and heart disease being seen as "a good way to go" (Walter et al 2004, Hallowell, in press). In this respect, deep vein thrombosis is close to heart disease, because it usually manifests as an identifiable "event," although the mortality associated with DVT is low (1-2\%) in comparison to myocardial infarction, but as many as $25 \%$ of patients with DVT will develop a postthrombotic syndrome (associated with chronic pain and other symptoms usually in the leg) and have a significant risk of reoccurrence (up to 30\%) over the next 10 years (Prandoni et al 1996).

A concern with regard to genetic testing is that it may fuel a fatalistic attitude that there is little that can be done to prevent or treat illness. A study on parents of newborns with familial hypercholesterolaemia (FH) found them to be fatalistic about the condition (Senior, Marteau, Peters, 1999), whereas adults with FH were observed to consider it to be controllable (Senior et al, 2002). It has generally been observed that individuals have a multifactorial understanding of familial risk of heart disease and cancer (Walter et al 2004). Efforts to use genetic susceptibility testing to encourage behaviour change have, however, produced mixed results; it has not been found to significantly motivate smoking cessation (Lerman et al, 1997; McBride et al, 2003), its effect on adherence to screening (mammography, colonoscopy) has been contradictory (Marteau \& Lerman, 2001), but 
individuals have been found to undertake simple venesection (letting of blood) to prevent iron overload in hemochromatosis (Meiser et al 2005). It has also been suggested that people may strive for symmetry between a perceived cause and a perceived effective treatment and be more prone to believe that a genetic risk is more amenable to biological treatment (medications) than lifestyle change (Marteau \& Weinman, in press).

In the medium term, genetic testing does not seem to have negative psychological consequences, even if the research is riddled with uncertainties (e.g. Broadstock et al, 2000). Qualitative studies have, however, brought into relief significant differences in how genetic risks are emotionally experienced. Research on genetic testing for Huntington’s disease (Smith et al, 2002) and hereditary breast and ovarian cancer (Hallowell, in press) have described intense experiences of fear for one's own and children's health provoked by witnessing relatives' prolonged suffering and death. Qualitative studies on experiences of testing for familial hypercholesterolaemia (Senior et al 2002) and hemochromatosis (Bharadwaj, 2002), on the contrary, have reported on many participants' perceiving the condition to be "manageable and controllable" or "inconsequential”.

At the social level genetic susceptibility testing is expected to bring public health benefits (Department of Health, 2003). However, it has also been argued that such tests may unnecessarily medicalise healthy "at risk" individuals, particularly in a situation when the tests are currently of uncertain validity and utility (Melzer \& Zimmern, 2002). Critics have also argued that genetic testing for susceptibility to common disease may overplay the role of genes and individual behaviour in the development of common 
illnesses and direct attention away from social causes, such as deprivation (see Lippmann, 1998, Petersen \& Bunton, 2002).

Furthermore, perceptions of risk and treatment and psychological impact of testing are influenced by how well individuals understand inheritance and their test results, which has proven challenging. Patients who had undergone genetic counselling for testing for Huntington's disease had a difficulty understanding and/or accepting the 50/50 chance of inheriting the condition from one parent (Smith et al 2002), and nearly half (45\%) of low-income African American research participants did not fully understand their results for a genetic test for a susceptibility to lung cancer (McBride et al 2002). A study on hemochromatosis testing found that nearly a third of participants did not recall how many mutations they had inherited (Meiser et al 2005), and 79\% of US patients tested for thrombophilia estimated their risk incorrectly (Hellmann et al 2003).

The discussion on genetic exceptionalism and research on perceptions of genetic risk highlight a number of issues. Information provided by genetic tests for conditions with low penetrance, for which effective preventative strategies exist, is considered less exceptional. Yet, there is scant research on how patients interpret this kind of information. The ability of genetics to deliver public health benefits depends on whether individuals take preventive measures to stave off disease; there is some research in this area, but it is not well understood how individuals interpret and choose preventive strategies. Furthermore, it has been suggested that genetic susceptibility tests may geneticize health or medicalise everyday life, but there is not much empirical evidence to support these suggestions. There are also no studies on whether patients, who have had a 
genetic test in mainstream medicine, without the involvement of clinical genetic services, feel they would have needed specialist or exceptional services.

Against this background we studied patients' experiences of testing for a low risk genetic susceptibility to DVTs in the UK.

\section{Methods}

To identify typical referral situations we first conducted a descriptive analysis of all the laboratory requests for factor V Leiden testing at the Royal Devon \& Exeter NHS Foundation Trust Molecular Genetics Laboratory during a two-year period in 2002-2004 ( $\mathrm{n}=390)$. We analysed the referrals in terms of their origin (primary or secondary care), reason for referral, gender and result.

Using the analysis of referrals as a guide, we invited a maximum variation sample of 97 individuals for a semi-structured qualitative interview via their referring doctor, either a consultant haematologist or a general practitioner. Qualitative methods were chosen because we were exploring a new area of patient experiences of testing for a genetic susceptibility. After obtaining ethical approval we conducted interviews with consenting respondents $(n=42)$ between January and November 2004. Most interviews took place in the participant's home. We adopted the format of discovery interviews (NHS Modernization Agency, 2001) and invited the participants to relate their experience of testing in a chronological order, which followed the natural flow of the participants’ narratives of illness or diagnosis from the time of being offered the test to how the participants reacted to and used the results and their perceptions of the process. The interview schedule provided a structure and included key elements of the testing 
experience and allowed time for participants to expand on other emerging issues that were important to them. The interviews were recorded and transcribed and coded for themes and subgroups of participants using NVivo qualitative software. The interviews were all conducted and interpreted by one experienced qualitative researcher; a sample of six interviews was read independently for themes and subgroups by two other members of the team to enhance the reliability of the coding-scheme.

\section{Results}

\section{Main Themes and Subgroup Spectrum}

Based on the analysis of laboratory referrals (for details see Authors 2006) patients from primary and secondary care, with a personal history of DVTs and with a family history of DVTs or thrombophilia and from different socioeconomic areas were invited to take part. Of the 97 patients invited, forty-two consented for an interview (see Table 1.). We received a good response (26) from individuals positive for one of the thrombophilia markers; ${ }^{3}$ most non-respondents had normal results, and only nine participants with normal results took part (seven were unaware of having had the test). This slanting towards individuals with positive results should be borne in mind when interpreting the findings. Of the 42 individuals interviewed 22 came from occupational classes I and II (including university students) and 20 from occupational classes III, IV and V (National Statistics, 1990); the majority (37/42) were women.

Table 1. (see Appendix 1.) 
In the initial interviews it emerged that patients did not consider that thrombophilia testing was special or "unusual”, even if it sought to detect for a genetic risk factor. Interviewees stated they thought it was much less serious than, for example, genetic testing for a predisposition to breast cancer. In subsequent interviews this theme was explored further by systematically asking the participants whether they thought the thrombophilia test was different because it was genetic, and whether they thought it would have been helpful to receive specialist genetic counselling prior to testing (none of the participants had been counselled by clinical genetic services).

We also discovered that participants' perceptions of the test lay on a wide spectrum of understanding. Some participants understood the test and its implications well; most of these participants were middle-class and well-educated, and they included both mid-life participants, who had experienced a DVT, and typically younger participants, who had had the test, because of family history of thrombophilia or DVTs. Some participants had a fair understanding of the test; for example, they might know they were positive but did not know which marker they had inherited in a situation, where different markers are associated with different risks. These participants were of mixed social class, and they had typically been referred to the test, because of family history of DVTs or thrombophilia. At the least informed end of the spectrum seven participants were unaware of having had a genetic test. These participants were all women, older than other participants and came from social classes III, IV and V; many of them had experienced several DVTs and/or cerebrovascular events and had poor health.

We have discussed the way in which the thrombophilia test was introduced and its results communicated contributed to poor understanding (Authors 2006). In this 
article we explore how participants made sense of the genetic nature of the test, taking into account how their different clinical histories and levels of understanding affected their perception of the test. We focus on three themes that emerged from the interviews on this issue: (i) whether the participants considered the results of the thrombophilia test different from or more serious than other medical information, (ii) how the participants used the genetic information, in particular whether and what preventive strategies they adopted, and (iii) whether participants considered specialist pre-test genetic counselling helpful or unnecessary.

\section{A Different Kind of Test?}

No [being genetic did not make the test different]. I mean, obviously, if it was a serious genetic disease then of course I suppose it would have done. But no, to me it's like, you know, testing for cholesterol or testing for umm ... I don't know, red blood cells or whatever [P13].

When asked, whether they thought thrombophilia testing was different, because it detected a genetic risk, participants often answered in the negative. This is illustrated by the statement above, made by a middle-aged professional woman, who had discovered she was factor V Leiden heterozygous after requesting the test because a relative had tested positive. Participants could emphasize the "ordinary" nature of the test by comparing it to other blood tests, such as cholesterol testing.

Most often participants made sense of thrombophilia by distinguishing it from other more "serious" conditions. A woman, who had undergone thrombophilia testing as 
part of many clinical tests, which revealed she had a leukemia with poor prognosis, put things into perspective by saying: "I wish I had this thrombophilia instead” (P31). Several young women, who had been referred to the thrombophilia test because of family history, made sense of it by defining it as less threatening than breast cancer genetics. They stated they would not undergo genetic testing for predisposition to breast cancer, describing breast cancer as "really serious" (P2) and noting they were also put off by the preventive treatments and would "not consider drastic surgery" (P1).

Two participants in their sixties, who had been referred to testing after a family member had tested positive and had both been recently diagnosed with diabetes 2, had a vague understanding of the condition and concluded that within the wider scheme of chronic illnesses of old age thrombophilia had little importance. As stated by the other one, a retired waitress:

I mean this year I've been diagnosed with diabetes, so already all these sorts of things are starting to happen to us. But we've got to this age and had good health so ... I just looked at it as something else you've just got to think about. But if I've had it all these years, and it hasn't been a problem, then I can't really see it being one. [P23]

Those participants, who were unaware of having had a thrombophilia test, were usually not overly concerned by the suggestion that they had had a genetic test without knowing it. Reflecting on genetic testing one of them stated: “I'm not against anything like that. I think it’s a good thing” (P26). Most of these participants had had 
several DVTs, poor health and had had many clinical tests and did not think a test identifying a familial risk would be different from other clinical tests.

These responses reflect the way in which participants made sense of the genetic susceptibility by comparing it to illnesses or diagnostic tests they had experienced or were aware, which has also been observed by Senior et al (2002) and Petersen (in press). The comparisons reflect the participants' efforts to make sense of the risk by locating it on a map of experienced or possible conditions and tests, which are associated with more frightening futures (leukaemia, HIV) or illnesses and treatments (breast cancer genetics), or have a more significant impact on everyday life (diabetes), are similar both in terms of manner of testing and implications (cholesterol) or are experienced as just one more of many diagnostic tests. These efforts to map the implications of thrombophilia in relation to a number of more and less serious, both non-genetic and genetic conditions indicate that individuals do not necessarily interpret a genetic susceptibility to belong to a different or exceptional category of conditions.

Participants, who had experienced a DVT or a pulmonary embolism (PE, clot in the lungs), were less likely to make sense of thrombophilia through comparing it with other diseases but focused on their event. All, except for one, of the participants, who had experienced a DVT and were aware of having had a genetic test, associated their event with an environmental trigger, such as a long flight, pregnancy, surgery, HRT or the Pill. The embodied experience had led these participants to emphasize the environmental trigger, or as one participant stated: “I’m fine unless I'm pregnant” (P28). Participants in this subgroup were also the strongest advocates of genetic testing to prevent DVTs. For example, a woman, a former teacher, who had gone on HRT and developed a PE, which 
went undiagnosed for days or possibly weeks, and resulted in serious complications stated:

To me, you see, there should really be a campaign, we should know, [the test] really should be done. ... I just feel, if I hadn't taken my HRT, I'd be better. [P19]

It has been observed that individuals have a multifactorial understanding of familial risk (Walters et al 2004), which in the case of individuals with thrombophilia, who had experienced a DVT, was further consolidated by an embodied experience of an environmental trigger.

Research has also indicated that family histories of illness and experiences of close relatives' death mediate people’s understanding of their personal risk (e.g. Walters et al 2004; Walters \& Emery, 2005; Hallowell, in press). Many of the participants, who had experienced a DVT, had not been aware of any family history. Some had asked their relatives afterwards and discovered, for example, that “in my mum's family there was quite a lot of thrombosis - my granddad's brothers and sisters” (P22). Those who had been referred to the test because of family history often had closer relatives, who had experienced a DVT. One participant's grandmother "had a big clot in her heart after she had a fall” and her mother had also had a DVT, but this was less serious or "been and gone” (P39). Still other participants were referred to the test after more distant relatives had complications; one woman reported that "this cropped up" when her granddaughter had some blood tests after "having trouble with her periods” (P20). The often scattered and unclear family histories of DVT, confounded by environmental triggers, such as 
accidents, probably account for many of the participants' lack of clear sense of personal vulnerability. This might be more generally indicative of experiences of low risk genetic susceptibilities, which rarely manifest themselves in severe personal or familial histories of illness.

A subgroup of participants, who had a strong family history of DVTs or a personal history of recurrent (up to nine) DVTs had different experiences. They were distressed as well as poorly informed about thrombophilia, lack of confirmation for thrombophilia (and not having an answer to the "why me" question, (P41)) or uncertainty about whether or not DVTs were "hereditary" (P35). A home maker, who had tested positive for a rare Antithrombin Deficiency, which is associated with significantly greater risk of a DVT than FVL, and had experienced multiple miscarriages and witnessed her mother die from a DVT and her grandmother and several of her mother's siblings having a DVT, was rather fatalistic about her risk:

I mean I'd like to think that there's something that would be there for you to take, for precautions. But obviously there isn't, so ... To me it's like, well, a time bomb. But like saying that, with my grandmother; she didn't die of a blood clot anyway, she died of lung cancer at 90. [P30]

The subset of stories on recurrent personal illness, strong family history and worry illustrate that testing for low risk genetic susceptibilities is likely to identify some patients at high risk, who may feel overwhelmed and confused, particularly without adequate information and support. 


\section{$\underline{\text { Uses of Genetic Information }}$}

The majority of the participants did not have a fatalistic attitude towards thrombophilia. The reason participants often thought thrombophilia was less serious than other medical conditions was that one could “do things” to prevent DVTs (P2).

Nearly all participants, who were aware of being positive for one of the thrombophilia markers, stated that one of the primary reasons that they had had the thrombophilia test was to inform their decision to take the combined oral contraceptive pill or HRT or to advice family members on the matter. Participants, who had sought thrombophilia testing after a relative was identified with one of the markers, often wanted the information in order to help them to decide whether or not to continue taking the pill as stated by a young woman attending a vocational college:

PS: ... you thought it would be a good idea to have the test?

I: Yes, of course ... because I don't want to get a blood clot like my mum. And also it's linked to the pill as well too.

PS Did [your doctor] tell you ... any other things that you should take into account?

I: Mmm, I think she mentioned something about flying in aeroplanes, but I don't fly in aeroplanes so. ... No, it was mostly about the pill. [P20] 
All participants, who were aware of having inherited one of the thrombophilia alleles, stated that they took precautions during long flights. The preventive actions ranged from "walking about after a period of time" (P18) to the decision of a young male university student with FVL, whose mother had a DVT after a long flight, to have a stop over on the US East Coast when flying to California (P8). The latter example also illustrates how participants often focused on preventative strategies that addressed the environmental trigger, which they perceived had caused their own or a close relative's DVT.

Participants were aware that lifestyle, such as smoking, being overweight, and not exercising, increased the chance of DVT. However, the majority of participants reported that they had not significantly changed their lifestyles as a consequence of thrombophilia testing. Those, who had led a healthy lifestyle continued to do so and felt they were doing the right thing, congratulating themselves for, for example, having "played squash, what, for 20 odd years or so" [P12].

Those who did not perceive themselves as leading a particularly healthy life often stated that they had tried to change their behaviour but not necessarily because of thrombophilia. Participants' stories about smoking were indicative of the complexity of life events, interpersonal and family relations, health, life course and social factors that played a role in their decisions to cease and relapse back into smoking. Only one participant stated that she had stopped smoking socially, because of the thrombophilia test. Other participants reported having stopped smoking when pregnant but "unfortunately" picking it up again afterwards, not being able to consider quitting because they had just divorced, feeling that quitting was difficult, having quit after being 
diagnosed with diabetes, after a parent had died of a heart attack or because cigarettes were expensive.

In situations where thrombophilia was mentioned in relation to life style change, it was usually not the only or most important motivator, which indicates how a genetic susceptibility may not necessarily motivate lifestyle change, but it may contribute to other events and factors that lead people to reconsider their habits, as in the case of a mid-life community care-worker:

PS: .. did it make you change any of your behaviours?

I: I cut down a bit 'cause I eat a lot of chocolate, I must admit. I eat an awful lot of chocolate. And I like, obviously, biscuits and things like that, so I have cut all that down ... and Andrew's [partner's pseudonym] diabetic, anyway ... But, yeah, I haven't stopped smoking, though, but we are both giving up after Christmas. That's more, I think, 'cause of Andrew's diabetes than anything. [P25]

The less informed participants did not significantly differ from the well-informed ones in terms of the preventive actions they had undertaken. However, less informed participants were uncertain about whether they were doing the right things or not, wondering, for example, "because it’s not like I'm a smoker ... I do a lot of sport, I don't drink, I mean I don’t know what else would affect it” (P42). Some of these participants stated that the fact that they did not know much was "a worry" (P30), whereas others said they knew some things and were "happy with that" (P37). 
Participants, who were unaware of having had the thrombophilia test and had had a DVT, were sometimes aware of some preventive actions, such as "coming off the HRT and taking the aspirin” (P15). However, because they were unaware of being tested they did not know about the possibility that their family members' might be at an increased risk of DVT and might benefit from preventive strategies. In the course of the interview, many stated they had been wondering about whether their children would develop a DVT and wanted to know more, as stated by a retired office clerk:

Yes, [I would like to know if there is a risk in my family] especially, if it might help my offspring ... Because our elder daughter has got very big legs. She's always had very sturdy legs but they ... they could give her problems, I think, later on. $[\mathrm{P} 26]$

Overall, the participants generally perceived DVTs to be preventable. The preventive strategies the participants chose suggest that they used genetic information to effectuate limited changes in their lives, such as decide about medications or take precautions during flights. The fact that participants did not change their lifestyle is disencouraging against the hope that genetic susceptibilities would encourage smoking cessation or healthier diet and exercise, and other studies have reported similar disencouraging findings (see Marteau \& Lerman, 2001, McBride et al 2002). However, participants’ accounts of prevention are encouraging against the fears that testing for genetic susceptibilities will lead people to live a medicalized life focused, in a nearly 
neurotic fashion, on risk prevention (Lippmann, 1998, Novas \& Rose, 2000, Petersen \& Bunton, 2002).

The fact that the participants interpreted prevention of DVTs mainly in terms of avoiding estrogen containing medications suggests that a biological test may lead people to adopt biological prevention strategies, focusing on medications, rather than change their lifestyle (Marteau \& Weinman, in press). It has been suggested that testing for genetic susceptibilities may lead to medicalization by encouraging people to consume potentially unnecessary medications (Melzer \& Zimmern, 2002). In the case of thrombophilia the focus on the Pill and HRT does not lead to medicalization but to a pharmacogenetic interpretation of prevention mainly in terms of avoiding certain pharmaceutical products. The Human Genetics Commission has suggested that pharmacogenetic tests should be defined as less exceptional when they are "used simply for the purpose of making prescribing decisions” (HGC, 2002: 54) The participants' almost disengaged attitude towards thrombophilia supports the Human Genetic Commission's claim that a test, interpreted as mainly pharmacogenetic, has limited impact on people's everyday lives. In the case of thrombophilia the "limited impact" has both positive and negative connotations in terms of not inducing neither worry nor healthy lifestyle.

\section{Need for Specialist Counselling}

One of the reasons genetic exceptionalism is discussed in policy-forums is that offering special services to individuals undergoing genetic testing is expensive. If some tests were categorised as less special they could be managed elsewhere e.g. in general practice. The 
participants had not received pre-test counselling by clinical genetic services and were asked, if they thought pre-test specialist genetic counselling would have been helpful. It has been observed that people may not know what genetic counselling means. For example, Skirton (2001) has observed that patients often expected not only information but also emotional understanding and support from genetic counsellors. We provided participants with an explanation that genetic counselling involved taking a family history and offering information about the test so that they could decide whether or not to take it. They were also told that the counselling would be done by someone specially trained to do so. Some participants associated counselling with psychological counselling to change behaviour, and one participant stated that she would not want counselling, saying “I am happy with the way I am” (P37). Several participants considered genetic counselling to mean persuading someone to take the test, saying it might be good for "some people" "so that they can realize the benefits of having the test" (P10). These different ways of interpreting genetic counseling, which partly reflect contradictions within practices of counseling itself (Clark, 1997) need to be borne in mind when interpreting the responses. Asking individuals’ opinions about any practice, such as genetic testing or counseling, which they have not experienced is bound to reflect lack of precise knowledge but can still generate valuable information about potential users’ perceptions, needs and preferences.

Participants had significantly different views about genetic counselling. Participants who were well informed and confident about their knowledge usually stated that they considered genetic counselling prior to thrombophilia testing unnecessary. On 
the contrary, participants, who had a vague understanding of the condition and its implications stated that they thought counselling prior to testing would have been useful.

Most participants made sense of genetic counselling by, again, comparing thrombophilia to other conditions, such as diabetes, HIV or predisposition to breast cancer, for which genetic counselling may or may not be offered. The well informed participants typically concluded that genetic counselling would be unnecessary, because thrombophilia was rather "inconsequential” in comparison with many other medical conditions. For example, a female student, who was diagnosed as diabetic at a young age and whose thrombophilia test came out as normal, considered the test to be less significant than her diagnostic test for diabetes:

Umm, I understand where they're coming from, but I would probably be a bit taken aback by being offered counselling because ... in my mind it's not ... I suppose because it came out negative, maybe if it came out positive I'd be a bit different, but I mean even when I was diagnosed with diabetes they didn't counsel me (laughs). It was just like, “Well, there you go” (laughs) (P1).

A young mother, who had done a humanities degree and was currently working as a waitress, reflected on genetic counseling against HIV testing and thought being referred to a specialist genetics counselor would not only be unnecessary but could also mislead patients about the seriousness of the test: 
I don't know [if I would have benefited from genetic counseling]. Because ... although it has an impact on your life it's not life threatening as such. ... like in HIV you get counseling .. And obviously that's ... a completely different ballgame, and I just think that I wouldn't want to have counseling ... that might make me think that that test goes in that group when it doesn't (P39).

The less informed patients, however, were of the opinion that genetic counselling would have helped them to understand what they were being tested for and what the implications of the test would be, as stated by a female financial analyst, who had been tested at a family planning centre:

PS Do you think that it would have been good to have kind of some sort of a counseling or whatever before you had any of these tests?

$R \quad$ Well, perhaps I suppose, $\mathrm{mmm}$, a more of an understanding of, ... actually what I was ... having tested for, because I mean, as I say, they took 5 phials of blood the first time and I didn't ... even know what Protein S was (P42).

Thus, some participants thought genetic counseling was not needed prior to thrombophilia testing, and some participants even thought referring patients to a specialist counseling would unnecessarily frighten them. In light of these answers the suggestions that genetic testing for susceptibilities to common disease could well be declared not exceptional and managed in mainstream medicine. However, the responses of the less informed participants, who felt that specialist counseling could have helped 
them to understand what they were being tested for and what the implications were, cast a doubt to the argument against exceptionalism. The responses raise the question of whether mainstream medicine is currently capable of managing genetic testing in a manner that does not produce a subgroup of patients with poor understanding, who can be perplexed, indifferent, worried or entirely unaware of having had a genetic test.

\section{Conclusion}

As also observed by other studies (Walter et al, 2004, Walter \& Emery, 2005, Senior et al, 2002, Petersen, in press), participants in our study made sense of the severity of their risk by comparing thrombophilia with other genetic and non-genetic conditions, by reflecting on their personal, embodied experience of a DVT, and by assessing their family history of DVTs. Our findings indicate that in a situation, where the illness is not perceived as most threatening, where it is associated with a definable and preventable environmental trigger, and where the susceptibility only rarely manifests itself in ubiquitous family stories or personal experiences of serious illness, a genetic risk factor is not interpreted as exceptional or grave. However, a subgroup of participants, some of whom had a strong family history of DVTs or a personal history of recurrent clotting and who often came from lower social classes, were distressed and/or confused about thrombophilia. This suggests that not all individuals, who had undergone thrombophilia testing, are at low risk or serene about the condition.

Participants did not interpret thrombophilia as "predicting” their health (Murray, 1997) but perceived DVTs as preventable. They had used the genetic test results to inform their decision making about the use of oral contraceptives and HRT and to 
advice family members on the matter. They had taken precautions during flights but had not otherwise changed their lifestyle. These findings suggests that, in the case of thrombophilia, hopes that testing for genetic susceptibilities will motivate people to change their lifestyle may be exaggerated, and similar findings have been reported in relation to other conditions (Marteau \& Lerman, 2001). However, the findings also indicate that testing for genetic susceptibility to deep vein thrombosis does not generally lead to a medicalisation or geneticization of everyday life (Lippman, 1998, Melzer \& Zimmern, 2002, Petersen \& Bunton, 2002).

The well informed participants' opinion that genetic counselling would be unnecessary or even unduly frightening prior to testing for thrombophilia support the suggestion that such tests could be managed in mainstream medicine. However, the fact that participants, who did not understand the thrombophilia test well, felt that counselling would have been helpful suggests that mainstream medicine may not currently be sufficiently prepared to manage genetic testing, particularly in the case of individuals, who are more worried, less educated or at a high risk.

Participants’ perceptions of thrombophilia generally indicate an emerging way of interpreting genetic information not as disclosing exceptional or “in depth” knowledge about one’s health and identity but as occasionally relevant "surface” knowledge (see Novas \& Rose, 2000: 508-509). Yet, the subgroup of worried participants suggests that not necessarily everybody has such a light-hearted attitude towards thrombophilia. Furthermore, our findings indicate that specific features of thrombophilia--such as individuals' perception of a DVT not as the most threatening disease and as associated with a specific environmental trigger and the availability of easy preventative 
strategies-account for the participants not unduly concerned attitude (also Walters et al, 2004). Individuals’ interpretation of a genetic risk of, for example, cancer may be different even if the numerical risk estimates were similar. Also our findings and other studies (Bharadwaj, 2002, Bharadwaj et al, in press, Senior, Marteau \& Peters, 1999, Senior et al, 2002) illustrate that some subgroups, such as individuals who are ill or parents of young children, may have different views from healthy at risk adults. Thus, our findings generally suggest that low risk genetic susceptibilities, for which preventive strategies exist, are not perceived as exceptional. Yet, they also emphasise the need to evaluate the personal implications of any such tests that may become available in the future on a case by case basis, paying particular attention to differences in experience between different groups. 


\section{References:}

Annas, G.J., Glantz, L.H., Roche, P.A. (1995). Drafting the genetic privacy act: Science, policy and practical considerations, Journal of Law, Medicine \& Ethics, 23, 36066.

Bharadwaj, A. (2002). Uncertain risk: genetic screening for susceptibility to haemochromatosis, Health, Risk and Society, 4, 3, 227-240.

Bharadwaj, A, Prior, L, Atkinson, P, Clark, A \& Worwood, M. (in press). The genetic iceberg: Risk and uncertainty in cancer genetics and haemochromatosis. In A. Webster (ed.). Innovative health technologies: Meaning, context and change. London: Palgrave/Macmillan.

Broadstock, M, Michie, S, Marteau, T. (2000). Psychological consequences of predictive genetic testing: A systematic review, European Journal of Human Genetics, 8, 731-738.

Clarke, A.J. (1997). The process of genetic counseling: beyond non-directiveness. In P. Harper and A. Clarke (eds.) Genetics, society and clinical practice. (pp. 179-200) Oxford: Bios Scientific Publishers.

Collins, F., Green, E., Guttmacher, A., Guyer, M.. (2003). A vision for the future of genomic research: A blueprint for the genomic era, Nature; 422: 835-847.

Department of Health (2003). Our inheritance, our future: Realising the potential of genetics in the NHS. London: The Stationary Office.

DeStefano, V., Rossi, E., Paciaroni, K. and Leone, G. (2002). Screening for inherited thrombophilia: indications and therapeutic implications, Haematologica, 87(10), 1095-108.

Everett, M (2004). Can you keep a genetic secret? The genetic privacy movement, Journal of Genetic Counselling, 13, 4, 273-291.

Green, MJ. and Botkin, JR. (2003). "Genetic exceptionalism” in medicine: Clarifying the differences between genetic and nongenetic tests, Annals of Internal Medicine, 138: $571-575$.

Grody, W., Griffin, J., Taylor, A., Korf, B., Hiet, J. (2001). American College of Medical Genetics consensus statement on factor V Leiden mutation testing, Genetics in Medicine, 3, 2: 139-148.

Haga, S., Khoury, M., Burke, W., (2003). Genomic profiling to promote healthy lifestyle: Not ready for prime time, Nature Genetics, 34, 4, 347-350 
Hallowell N, Foster C, Eeles R, Ardern-Jones A and Watson M (2004). Accommodating risk: responses to BRCA $1 / 2$ genetic testing of women who have had cancer. Social Science and Medicine, 59(3), 533-565

Hallowell, N. (in press). Varieties of suffering: Living with the risk of ovarian cancer, Health, Risk and Society.

Hellmann, EA., Leslie, ND., Moll, S. (2003). Knowledge and educational needs of individuals with the factor V Leiden mutation, Journal of Thrombosis and Haemostasis, 1, 11: 2335-39.

Human Genetics Commission. (2002). Inside information: Balancing interests in the use of personal genetic data. A Report.

Hunt, K., Emslie, C., Watt, G. (2001). Lay constructions of a family history of heart disease: potential for misunderstandings in the clinical encounter, Lancet; 357:1168-1171.

Lippman, A. (1998). The politics of health: Geneticization versus health promotion. In The politics of women's health: Exploring agency and autonomy. Philadelphia: Temple University Press.

Marteau, T \& Lerman, C. (2001). Genetic risk and behavioural change, British Medical Journal, 322, 1056-59.

Marteau, T \& Weinman, J. (in press). Self-regulation and the behavioural response to DNA risk information: A theoretical analysis and framework for future research, Social Science and Medicine.

McBride, C, Bepler, G, Lipkus, I, Lyna, P, Samsa, G, Albright, J, Datta, S, Rimer, B. (2002). Incorporating genetic susceptibility feedback into a smoking cessation program for African-American smokers with low income, Cancer Epidemiology Biomarkers \& Prevention, 11, 521-28.

Meiser B., Dunn S., Dixon J., Powell, L.W., (2005) Psychological adjustment and knowledge about hereditary hemochromatosis in a clinic-based sample: A prospective study, Journal of Genetic Counselling, 30.

Melzer, D. and Zimmern, R. (2002). Genetics and medicalisation, British Journal of Medicine, 324(7324): 863-4.

Middeldorp, S., Meinardi, J., Koopman, M., Van Pampus, E., Hamulyak, K, van der Meer, J., Prins, M. and Büller, H. A prospective study of asymptomatic carriers of 
the Factor $\mathrm{V}$ Leiden mutation to determine the incidence of venous thromboembolism, Annals of Internal Medicine, 2001; 135, 5: 322-327.

Murray, T. (1997). Genetic exceptionalism and "future diaries": Is genetic information different form other medical information, In M. Rothstein (ed.) Genetic secrets: Protecting privacy and confidentiality in the genetic era (pp. 60-73). New Heaven, CO: Yale University Press.

National Statistics (1990). Standard occupational classification. Available at: http://www.statistics.gov.uk/methods_quality/ns_sec/soc2000.asp

Novas, C. and Rose, N. (2000). Genetic risks and the birth of the somatic individual, Economy and Society, 29, 4, 485-513.

NHS Modernization Aagency. (2001). Discovery interviews. Available at: http://www.modern.nhs.uk/improvementguides/patients/5_5.html

Petersen, A. (in press). The best experts: The narratives of those who have a genetic condition, Social Science and Medicine.

Petersen, A. and Bunton, R. (2002) The new genetics and the public's health. London: Routledge.

Prandoni, P, Lensing, AW, Cogo, A, Cuppini, S, Villalta, S, Carta, M, Cattelan, AM, Polistena, P, Bertina, E, Prins, MH. (1996). The long-term clinical course of acute deep venous thrombosis, Annals of Internal Medicine, 125:1-7.

Ross, LF. (2001). Genetic exceptionalism vs. paradigm shift: Lessons from HIV, Journal of Law, Medicine and Ethics, 2001; 29: 141-148.

Rothstein, M. (2005). Genetic exceptionalism \& legislative pragmatism, Hasting Center Report, 35, 4, 27-33.

Secretary's Advisory Committee on Genetic Testing (SACGT). Development of a classification methodology for genetic tests. Bethesda. 2001. Available at: http://www4.od.nih.gov/oba/sacgt.htm

Senior, V., Smith, J. and Michie, S. and Marteau, T. (2002). Making sense of risk: An interpretative phenomenological analysis to vulnerability to heart disease, Journal of Health Psychology, 7(2), 157-168.

Senior, V, Marteau, T, Peters, T. (1999). Will genetic testing for predisposition for disease result in fatalism? A qualitative study of parents responses to neonatal screening for familial hypercholesterolaemia, Social Science and Medicine, 48(12):1857-60. 
Smith, J., Michie, S., Stephenson, M and Quarrel, O. (2002). Risk perception and decision-making in candidates for genetic testing for Huntington's disease: An interpretative phenomenological analysis, Journal of Health Psychology, 7(2), 131-144.

Skirton, H. (2001). The client's perspective of genetic counseling-A grounded theory study, Journal of Genetic Counselling, 10(5), 311-329.

UK Genetic Testing Network. (2003). A list of tests offered by the UK GTN laboratories, UK Genetic Testing Network, available at: http://www.ukgtn.org/directory.html

Walker, I., Greaves, M., Preston, F. (2001). Guideline: Investigation and management of heritable thrombophilia, British Journal of Haematology, 114: 512-528.

Walter, F, Emery, J, Braithwaite, D, Marteau, T. (2004). Lay understanding of familial risk of common chronic diseases: A systematic review and synthesis of qualitative research, Annals of Family Medicine, 2(6), 583-594.

Walter, F, Emery, J. (2005). “Coming down the line”: Patients’ understanding of their family history of common chronic diseases, Annals of Family Medicine, 3(5), 405-414.

Watkins, H. \& Farrall, M. (2006). Genetic susceptibility to coronary artery disease: from promise to progress, Nature Reviews Genetics, 7(3):163-73

\footnotetext{
${ }^{1}$ Individuals who are heterozygous (inherited the allele from one parent) for FVL have a low risk of DVTs, individuals who are homozygous (inherited the allele from both parents) have a more significant risk of DVTs.

2 There are no statistics on how many individuals are tested for FVL annually in the UK; according to the statistics of UK Genetic Testing Network (UKGTN, 2003), approximately 1500 tests for FVL were processed in its laboratories in 2003, which makes it one of the most common genetic test. However, the numbers are likely to be much higher as many biochemical and DNA-based tests for thrombophilia are processed in haematology laboratories, which are not covered by the UKGTN.

${ }^{3}$ Participants had usually been referred for a thrombophilia screen, which identifies the thrombophilia markers FVL, prothrombin, protein C deficiency, protein S deficiency and antithrombin deficiency.
} 


\section{Appendix 1.}

\begin{tabular}{|c|c|c|c|c|c|c|}
\hline $\begin{array}{l}\text { Self-reported } \\
\text { reason for referral/ } \\
\text { Test result }\end{array}$ & $\begin{array}{l}\text { Personal } \\
\text { history of } \\
\text { DVTs } \\
\end{array}$ & $\begin{array}{l}\text { Family } \\
\text { history of } \\
\text { thrombophilia }\end{array}$ & $\begin{array}{l}\text { Family } \\
\text { history } \\
\text { of DVTs }\end{array}$ & Other & Unknown & Total \\
\hline Factor V Leiden & 6 & 8 & 1 & 1 & & 16 \\
\hline $\begin{array}{l}\text { Other thrombo- } \\
\text { philia markers }\end{array}$ & 1 & 2 & 1 & 1 & & 5 \\
\hline $\begin{array}{l}\text { Positive, marker } \\
\text { unknown }\end{array}$ & 1 & 3 & 1 & & & 5 \\
\hline Normal & 2 & 2 & 2 & 3 & & 9 \\
\hline Unknown & & & & & 7 & 7 \\
\hline Total & 10 & 15 & 5 & 5 & 7 & 42 \\
\hline
\end{tabular}

Table 1. Characteristics of participants 